\title{
David Oliver: In support of acute internal medicine
}

\author{
David Oliver consultant in geriatrics and acute general medicine
}

Berkshire

The diabetologist Partha Kar recently wrote a provocative blog post questioning the rationale for acute internal medicine (AIM) existing as a specialty. ${ }^{1}$ Kar said that he meant to raise debate and ask questions, not to cast doubt, saying that acute physicians shouldn't take it personally. Meanwhile, a nephrologist, Dr Ross, wrote a journal letter that appeared to disparage AIM specialists and their close cousins, acute geriatricians. ${ }^{2}$

As a geriatrician, like most other UK hospital physicians working in big "ologies" including nephrology and diabetes, I trained, dually accredited, and gained extensive experience in general internal medicine, including years of unselected general take responsibilities. ${ }^{3}$

As a consultant, combining this with daily specialty work and specialty on-call rotas can cause tensions. It can also spark local resentments about which specialty plays a big enough acute role or should remain on the rota. With so much AIM provided by doctors not certified in it, Kar asked what value the separate specialty of AIM adds.

In the UK, AIM as a specialty gained momentum partly from the four hour performance target in emergency departments. Acute medical units, clinical decision units, and medical admissions units sprang up.

There's a growing evidence base for dedicated acute medicine models. ${ }^{4}$ And patients requiring a slightly longer but time limited stay are surely better in a more ward-like area for initial assessment and treatment. We should also divert far more patients to ambulatory emergency care chairs than to beds. ${ }^{5}$

Acute medicine and geriatrics have led the way in such "front door" models, with a relentless focus on care pathways, interfaces, and patient flow; "home first" initiatives; acceptance of risk; use of multidisciplinary teams and protocols; avoiding admission to deeper wards; improving patient flow and bed occupancy; and minimising harms associated with admission. ${ }^{6-8}$ As the core business and values of acute medicine centre on this front door and ambulatory work, AIM specialists can devote more attention, training, and expertise to it than doctors dipping into the general intake rota episodically as an add-on to their day job, with varying enthusiasm. Doctors formally accredited in acute medicine must undertake (among others) placements in emergency medicine, cardiology, intensive care, and geriatric medicine. In turn, they're comfortable dealing with complex, acutely deteriorating or critical patients and expediting rapid discharge across interfaces. ${ }^{910}$

Skilled "expert generalism," not based around organ systems or procedures, has often struggled against unfair perceptions

AIM is a young specialty, and the UK has only about 640 consultants, compared with over 1000 in several specialties where doctors dually certify in internal medicine-although the "Take AIM" campaign aims to draw more in. ${ }^{11}$ But every specialty has to start somewhere. Skilled "expert generalism," not based around organ systems or procedures, has often struggled against unfair perceptions, as geriatricians and emergency medicine doctors know from experience.

Many UK hospitals don't have enough doctors for a take model predominantly run by acute medicine/geriatrics to be a reality, so hybrid models are still the norm. But a lack of acute physicians doesn't invalidate the rationale for AIM as a separate specialty. The rest of us need to contribute to the take and refrain from dismissive attitudes.

Competing interests: See www.bmj.com/about-bmj/freelancecontributors/david-oliver.

Provenance and peer review: Commissioned; not externally peer reviewed.

Follow David on Twitter: @mancunianmedic

Kar P. Full circle? 9 July 2017. http://nhssugardoc.blogspot.co.uk/2017/07/full-circle.html. Ross CN. Now, where are those matches at the end of this tunnel? Future Hosp $J$ 2017;4:151-2. http://futurehospital.rcpjournal.org/content/4/2/151.2.full.

3 Royal College of Physicians. 2015-16 census (UK consultants and higher specialty trainees). 7 Dec 2016. https://www.rcplondon.ac.uk/projects/outputs/2015-16-census-ukconsultants-and-higher-specialty-trainees.

4 Jones $\mathrm{M}$. The evidence for acute internal medicine and acute medical units. Future[abstract]. Hosp J 2016;358:45-8. http://futurehospital.rcpjournal.org/content/3/1/ 45.

5 Oliver D. David Oliver: Acutely ill patients on trolleys and beds-why not chairs?BMJ 2016;358:1684. doi:10.1136/bmj.i1684 pmid:27012582.

$6 \quad$ NHS Improvement. Good practice guide: focus on improving patient flow. 14 July 2017. https://improvement.nhs.uk/resources/good-practice-guide-focus-on-improving-patientflow/. 
7 NHS Acute Frailty Network. Acute Frailty Network (AFN) - supporting people with frailty and urgent care needs to get home sooner and healthier. https://www.acutefrailtynetwork org.uk/.

8 Oliver D, Burns E. Geriatric medicine and geriatricians in the UK: how they relate to acute and general internal medicine and what the future might hold? Future Hosp J 2016;3:49-54 www.bgs.org.uk/pdfs/2016_rcp_future_hospitals.pdf.

9 Royal College of Physicians. Medical care. 17 May 2017. https://www.rcplondon.ac.uk projects/outputs/medical-care- 0 .
10 Royal College of Physicians. Specialty spotlight-acute internal medicine (AIM). 3 Nov 2014. https://www.rcplondon.ac.uk/education-practice/advice/specialty-spotlight-acuteinternal-medicine-aim

11 Take AIM website. http://takeaim.org.uk/.

Published by the BMJ Publishing Group Limited. For permission to use (where not already granted under a licence) please go to http://group.bmj.com/group/rights-licensing/ permissions 